\title{
Voltage Protection and Harmonics Cancellation in Low Voltage Distribution Network
}

\author{
${ }^{1}$ Prof. Amruta Bijwar, ${ }^{2}$ Prof. Madhuri Zambre \\ ${ }^{1}$ Professor, Department of Instrumentation Engineering, Government College of Engineering \\ Amravati, India \\ ${ }^{2}$ Professor, Department of Electrical Engineering, P.E.S Modern College of Engineering Pune India \\ lamrutabijwar@gmail.com \\ ${ }^{2}$ madhurizambre01@gmail.com
}

\begin{tabular}{|l|l|}
\hline Article History & \multicolumn{1}{c|}{ Abstract } \\
$\begin{array}{l}\text { Article Submission } \\
\text { Revised Submission } 2018\end{array}$ & $\begin{array}{l}\text { Nowadays low voltage distribution network is considered as worldwide future } \\
\text { generation distribution network. But the major concern is harmonics generation and } \\
\text { steps taken to cancel those harmonics. In our proposed work, low voltage } \\
\text { distribution network is designed with low voltage and harmonics are cancelled in } \\
\text { Article Accepted } \\
29 \text { November } 2018 \\
\text { Article Published } \\
3 I^{\text {st }} \text { December } 2018 \\
\text { our method. The combination of current control unit and voltage control unit will } \\
\text { give extra reliable power solution to increase the required capacity of low voltage } \\
\text { grids. The high voltage protection gears are used in worst environment for low } \\
\text { voltage and low current distribution network test is preferable to assess a variety of } \\
\text { operation uniqueness. Therefore, it has few restrictions in implementation of } \\
\text { economic in addition to process methodologies. In our work a 48V direct current } \\
\text { base up-scale low voltage distribution network test is urbanized to allow the copy } \\
\text { and surveillance of a variety of phenomenon of direct current distribution networks. } \\
\text { The proposed system provide stretchy pattern ability by introduce S-connectors and } \\
\text { T-connectors module that will be proscribed distantly, and near real time monitor } \\
\text { function through by means of a data acquisition system associated toward the nodes. } \\
\text { Each connector be able to calculate Power, Voltage and current with up to 250 kHz } \\
\text { frequency. To calculate power quality and to understand the performance of the } \\
\text { distribution network, frequency analysis is required along with collected data. } \\
\text { Keywords: Grid, Network, Voltage, Harmonics, Power generation }\end{array}$ \\
\hline
\end{tabular}

\section{Introduction}

LVDC distribution networks, unlike the conventional AC distribution networks, have different characteristics in voltage by having no base frequency[1]. Many studies have been conducted on the adoption of the LVDC distribution mostly focusing on improved distribution efficiency of electricity, high power quality (PQ) and reliability. LVDC distribution network is designed to support flexible configuration with remotely controlled switch nodes that are called as S-connectors and T-connectors. A real-time monitoring system is attached to collect voltage and current data from the nodes with the maximum sampling speed of $250 \mathrm{kHz}$. To observe the effect on $\mathrm{PQ}$, frequency analysis is performed using VRTR. Therefore, the harmonic mitigation techniques are very important to improve the quality of grids.

The designed network will divide low voltage distributed network and centralized systems. Low voltage distributed networks are frequently installed toward supply power on the way to close by customers whether or not their owners, whereas centralized voltage distributed network act correspondingly to the power stations and are frequently coupled to higher current than the low current level small grids[2].At present there are different harmonics mitigation techniques electric system levels to get better grid current and voltage waveforms. The harmonic mitigation techniques are classified as passive techniques. The economic in addition to ecological 
compensation coupled by means of these low voltage distributed network, their virtual collision on low voltage distributed network grids has so far to be methodically investigate, mainly as the location of these units cannot exist forbidden by distribution system operators in addition to their output voltage is stochastic as well as nondisposable. Tesla has indicated the functional advantages of elective stream.

Transformers made it simple to build the AC voltage. This permitted the ability to be transmitted over significant distances with insignificant harm. This is certifiably not a significant communicated misfortune. Tesla's pragmatic outcomes are in any event a main factor for the $\mathrm{AC}$ framework. This discussion has become visible again because of the ongoing improvement of intensity gadgets that utilize transmission lines with high voltage DC associations. High Voltage DC Transmission permits you to consume more control over significant distances with less harm contrasted with AC transmission. Nevertheless, a higher low voltage distributed network diffusion might cause difficulty in control and operation of small grids. Along with the challenges connected with low voltage distributed network are: number of the grid components, such as low power transformers and cables[3]. To observe the effect on PQ, frequency analysis is performed using VRTR. Therefore, the harmonic mitigation techniques are very important to improve the quality of grids.

The LVDC distribution network testbed uses 48VDC downscale voltage and consists of up/down power convertors, S-connectors, and T-connectors. S-connectors serve as the switches of the distribution network. Force Electronics empowers effective and precise control of electrical force. Air conditioning to DC proficient AC, DC to AC, DC to DC transformation innovation is presently accessible in the market, where DC to DC change is more effective than AC to DC change. The quantity of gadgets working in DC is expanding in homes and workplaces. Most gadgets use DC inside, which requires an AC to DC switch between the AC gracefully and the DC side of the gadget. Instances of these gadgets are PCs, radios, TVs, phones and other electronic gadgets. Vitality stockpiling gadgets such as batteries, cell phones and cordless gadgets require direct stream as a vitality source. They are outfitted with connectors that convert $230 \mathrm{~V}$ AC to low voltage DC. There is lost these AC-to-DC transformations. Some DC gadgets require an extremely productive DC-to-DC converter to work. A DC gracefully chain in the living arrangement assists with limiting electro-attractive obstruction and to limit the harm brought about by an absence of receptive vitality, while requiring less current to transmit a similar measure of vitality. For safe utilization of DC voltage without endorsed protecting safety measures the voltage ought not surpass $50 \mathrm{~V}$.

\section{Literature Review}

In AC systems, the standardized definition such as IEC 61000-4-30/4-15, IEEE1159/1549 and EN50160 are used to manage the power quality. The indices for the major PQ by the afore-mentioned standard can be categorized as transient, interruption, sag/under-voltage, swell/overvoltage, distortion, voltage fluctuation, and frequency variation[4]. In general, some $\mathrm{PQ}$ measurement parameters used in the $\mathrm{AC}$ distribution network are still required even in the LVDC distribution network although some other parameters are only related to AC systems. The fundamental frequency that is usually $50 \mathrm{~Hz}$ or $60 \mathrm{~Hz}$ only holds meaning in AC networks. LVDC distribution network consists of various power conversion devices that use power switching devices such as a converter, switching power supply, and battery charger. Therefore, the effects of disturbance such as the inrush current, harmonics, and electromagnetic interference (EMI) appear to be high.

Most apparatuses utilized in homes and workplaces require just negligible power and can be legitimately associated with a low-voltage DC gracefully framework after evacuation. Most economically accessible gadgets are planned with an information voltage of $24 \mathrm{~V}$ and $12 \mathrm{~V}$ and a few gadgets accompany an information voltage of $50 \mathrm{~V}$ as low voltage $\mathrm{DC}$ gadgets have a high dielectric request which fundamentally diminishes feed misfortune. An LVDC distribution network testbed is developed to replay and monitor various phenomena in DC distribution systems. The LVDC distribution network testbed uses 48VDC downscale voltage and consists of up/down power convertors, S-connectors, and T-connectors. S-connectors serve as the switches of the distribution network allowing topology changes. T-connectors play the role of the branches of the distribution network and links of the 
distribution line to power convertors connecting loads and generators with a number of power electronics, and reduced cost, in terms of system control[5].

It has been observed that the measurement of the distribution network is performed using the voltage and current sensors embedded in S-and T-connectors. The current sensors are designed to measure the current of all branches including the ground. The measured values of voltage and current of the distribution network are collected through RS-485 with $250 \mathrm{kHz}$ sampling rates by using a 128 channel data acquisition (DAQ) board[6].The collected data are transmitted through TCP/IP to the main data collection unit (mDCU). An LVDC distribution network usually includes the switching power devices for electric power conversion such as converters and inverters. Electromagnetic waves are generated due to high-frequency components in the band of $30 \mathrm{MHz}$ or less by the operation of the switching device.

The need to analyze signals up to $150 \mathrm{kHz}$ for EMI consideration because of the power switching devices. In addition, the effect of an electromagnetic wave due to the arc discharge may appear in the frequency band higher than $30 \mathrm{MHz} 9$. This electromagnetic noise can cause malfunctions and interferences with the wireless service such as a control device and electric and electronic equipment. Therefore, the LVDC distribution network test bed environment requires a variety frequency analysis. This study conducts the frequency analysis for $100 \mathrm{~Hz} \sim 25 \mathrm{kHz}$ and $100 \mathrm{~Hz} \sim 100 \mathrm{MHz}$ bands. It is concluded that the voltage FFT analysis result for the load variations over time increasing the DC distribution network current from 0 to $2 \mathrm{~A}$ by increasing loads attached to the network[7].

The dc distribution system has a FFT analysis on the voltage, the main frequency components are observed in 15 $\mathrm{kHz}$ and $20 \mathrm{kHz}$. Especially, the amount of the frequency component at $15 \mathrm{kHz}$ increases as the load increases showing the characteristics of PCS attached to the load [8]. Low voltage noise generates up to $70 \mathrm{MHz}$ band. Therefore, it may be necessary to observe up to $70 \mathrm{MHz}$ signals in the LVDC distribution network testbed environment to understand the DC distribution network phenomena at high-frequency such as EMI with additional equipment [9]. The average load attached to the DC distribution network via a dc/dc converter is varied to change the distribution network current from 0 2A to verify the phenomena that occur in the distribution network by the load changes [10]. All approaches which is used to protect the voltage in low voltage distribution systems have harmonics and which is unavoidable. In most cases harmonics are reduced but never made zero.

\section{Proposed Methodology}

In our proposed method, a low voltage distribution network with power loss is designed and we proposed a method to eliminate the harmonics generated in it. The designed low voltage distribution system is shown if Figure 1.

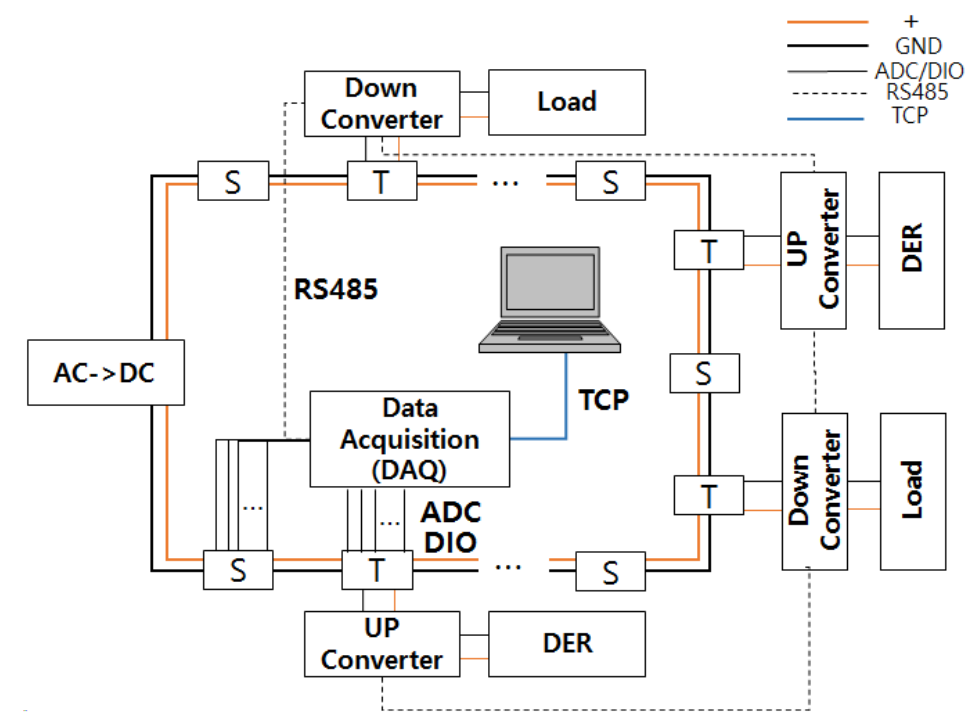

Fig 1: Low voltage distributive network 
Our network has four types of converters i.e., step up and down converters. This network has data acquisition system which will store all previous data involved in it and in turn warns the network whenever there is power fluctuations. When a grid is connected to it, power fluctuation will become regular. In order to avoid it we use capacitive loads. By using these loads DC power will be normalized so that only AC will be reason for harmonics. Two pairs of S and T converters are used to avoid over load even more than one grid is connected. Time taken for servicing the network without shutting down the unit is also possible. This network will work with both 3phase and 1 phase as well. This distribution network typically include the switch devices for power adaptation such as converters and inverters.

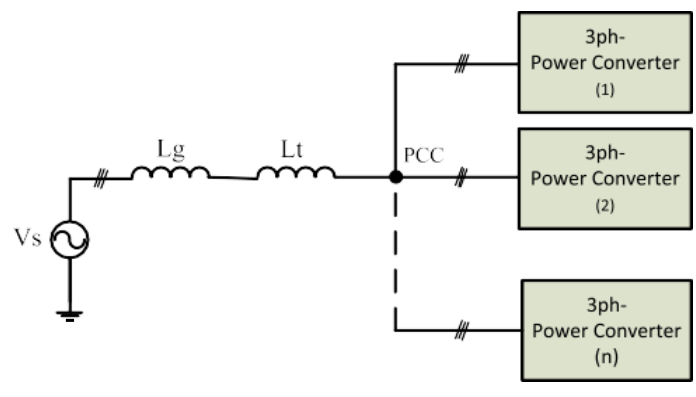

Fig 2: Grid Connection with converters

Two pairs of A to D converters are used to avoid uneven harmonics even more than one grid is connected as shown in Figure 2. The battery power storage center plays an important role in stabilizing the load bus voltage and DC bus voltage. In the SST-based DG grid connection, the battery power storage station can stabilize the load bus voltage and DC bus voltage after the shot. The circuit breaks down and there is only slight oscillation as shown in Figure 3. After the relay protection functions, the DC bus voltage due to the operation of the power storage station is controlled to the actual rating value, eliminating the voltage climbing phenomenon.

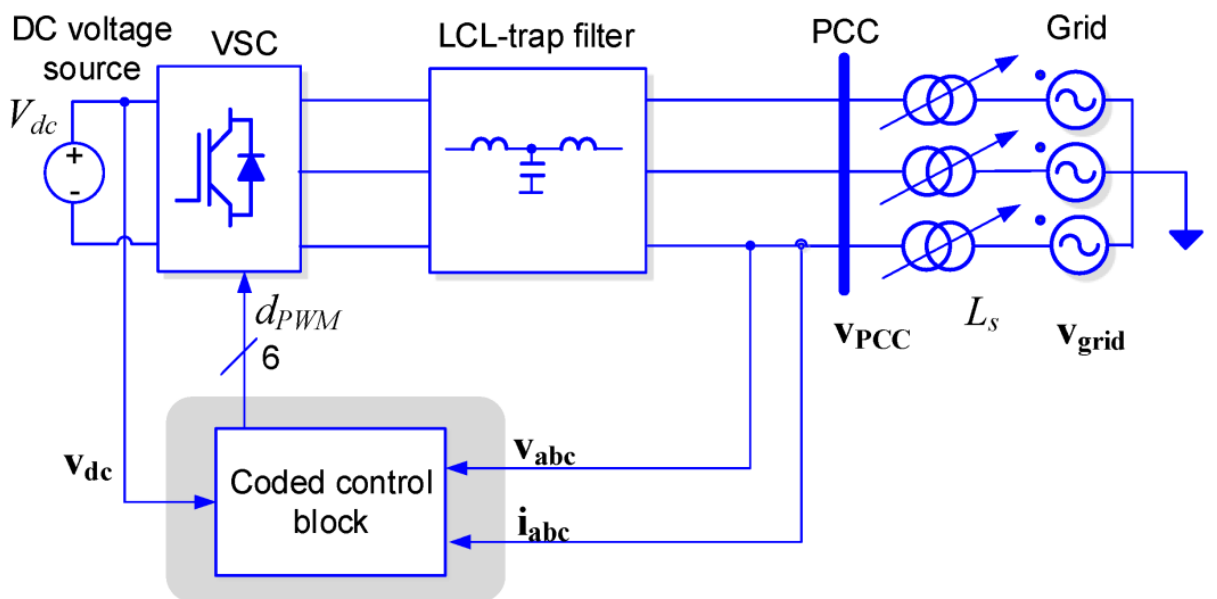

Fig 3: Schematic of DC Grid connection

\section{Simulation Results}

The harmonic performance of a converter which has multi parallel power is analyzed low voltage distribution network level; it is significant to comprehend the harmonic abolition method of converters connected in parallel at a PCM. Therefore simulation has done to show mechanism involved in harmonic elimination of the converters connected in parallel. Then in system level simulations were done the output is shown in Figure 4a-4c. 


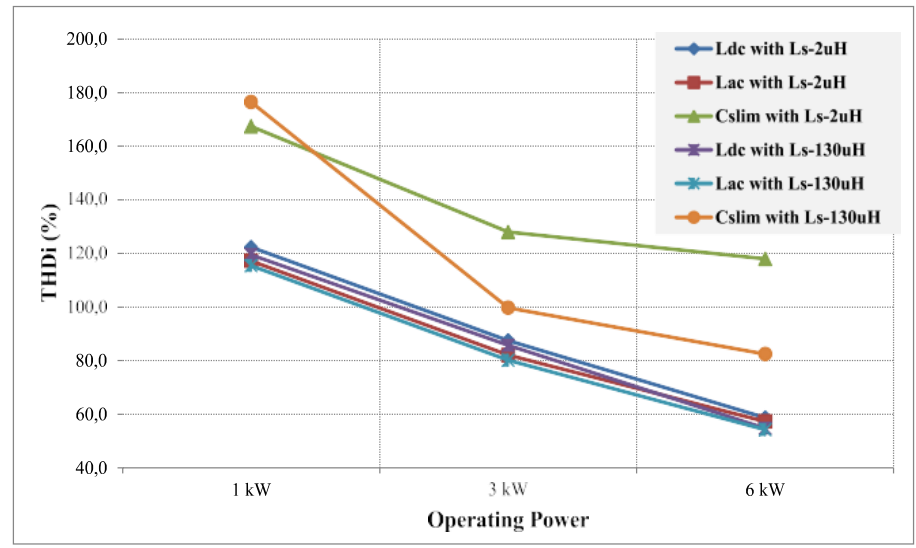

(a)

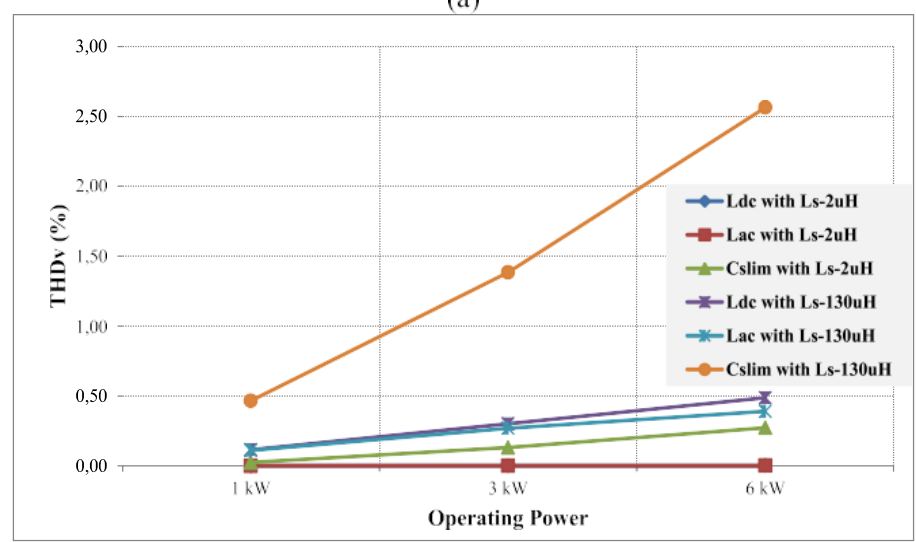

(b)

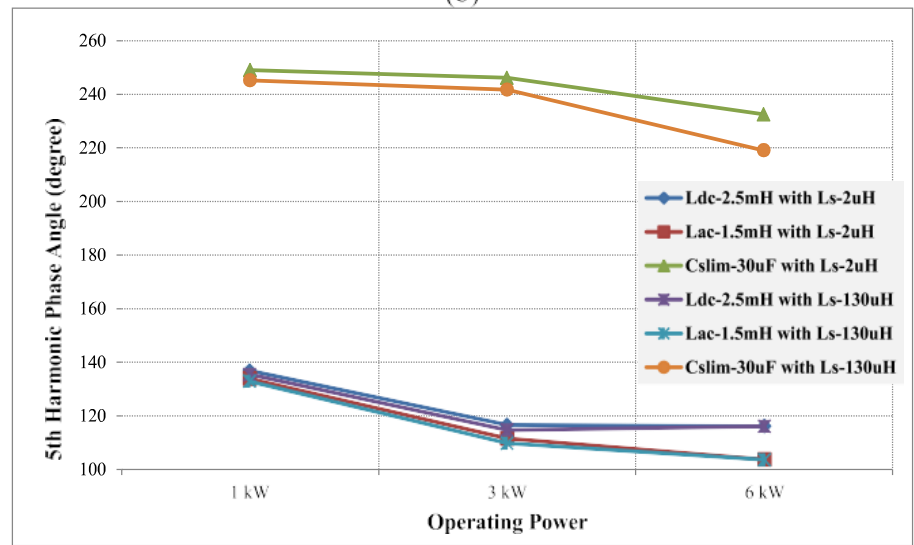

(c)

Fig 4: Simulated outputs of the proposed method

The results are obtained by simulating $901 \varnothing$ converter components operating at 3 similar power levels which had simulated in MATLAB. Furthermore 5th voltage harmonics with different phase angles value have been detected at the PCM. From the multiunit examination, deviation in the 5th voltage harmonic with different phase angle by small grid is from $\left(200^{\circ}-122^{\circ}\right)$ and for soft grid is from $\left(120^{\circ}-260^{\circ}\right)$.

The below Table 1 shows the effectiveness of low voltage distribution network with various phase angles and number of grids connected to it. From the simulation results it is proved that our proposed system will not have any impact on number of grids connected and with different phase angles. Our method will find faults in the gris as shown in Figure 5. 


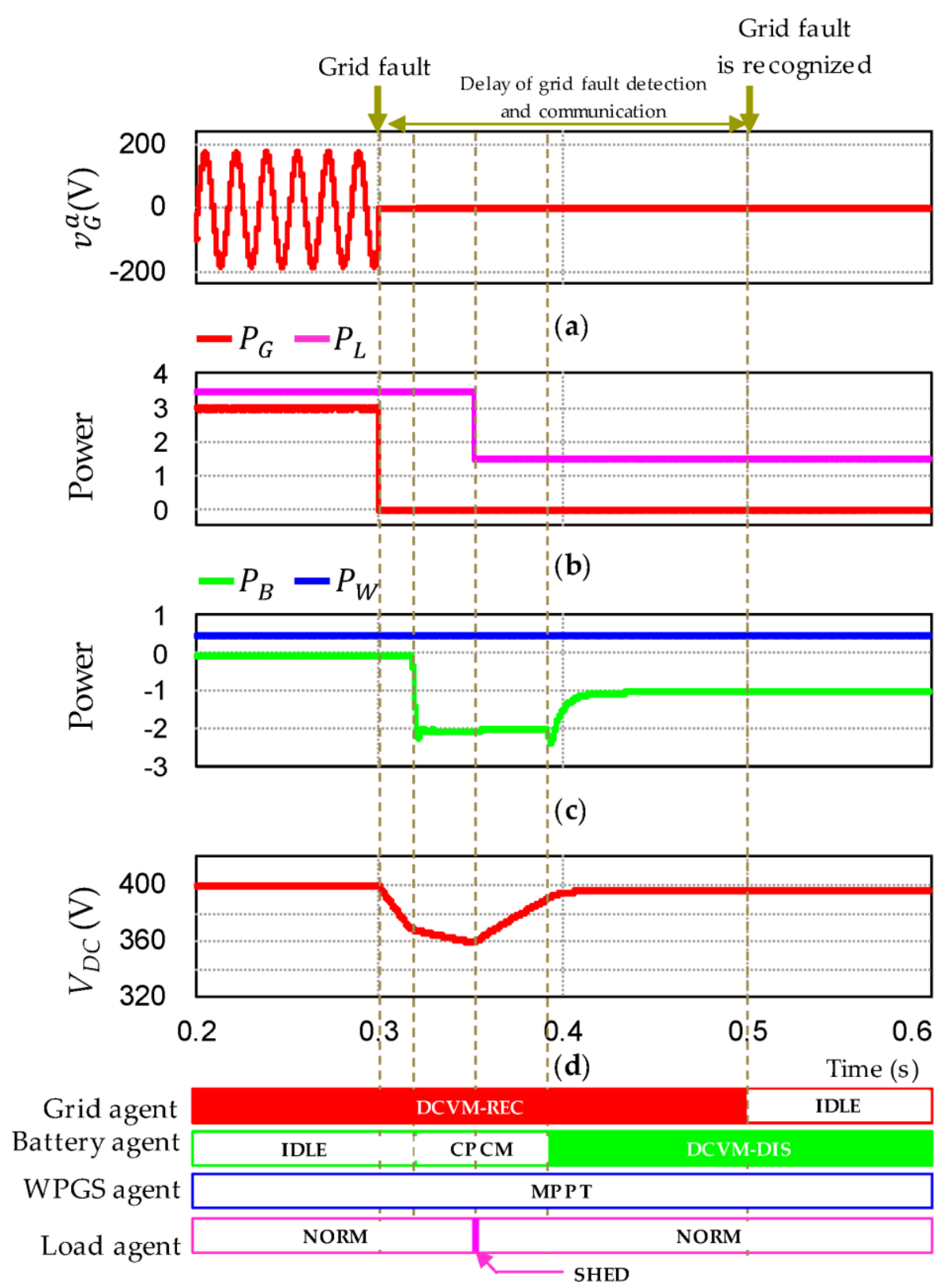

Fig 5: Simulated outputs of Identification of Faults in grid

This is interesting to discuss the Single -phase converter system, the fifth current harmonic phase angles variation are close to the single unit system. On the other side, the different phase angle difference for single-phase system is from $\left(54^{\circ}-106^{\circ}\right)$, which is counter phase to the three-phase converter.

TABLE I Simulated Values of low voltage distributive network

\begin{tabular}{|c|c|c|c|c|c|}
\hline Grids & $\begin{array}{c}\text { Difference in } \\
\text { Phase } \\
\text { angle(Degrees) }\end{array}$ & $\begin{array}{c}\text { Voltage Drop } \\
(\mathbf{v})\end{array}$ & $\begin{array}{c}\text { Frequency } \\
(\mathbf{H z})\end{array}$ & THD & $\begin{array}{c}\text { Operating power } \\
\text { (W) }\end{array}$ \\
\hline Grid 1 & 20 & 13 & 150 & 122 & 5 \\
\hline Grid 2 & 18 & 15 & 148 & 113 & 5 \\
\hline Grid 3 & 21 & 12 & 155 & 115 & 5 \\
\hline
\end{tabular}




\begin{tabular}{|l|l|l|l|l|c|}
\hline Grid 4 & 23 & 09 & 146 & 123 & 6 \\
\hline Grid 5 & 12 & 21 & 158 & 156 & 5 \\
\hline Grid 6 & 14 & 19 & 152 & 178 & 4 \\
\hline Grid 7 & 17 & 17 & 150 & 154 & 5 \\
\hline Grid 8 & 19 & 22 & 149 & 121 & 6 \\
\hline
\end{tabular}

\section{Conclusion}

The most important power factor issue is to control the voltage and current fluctuations in a grid when it is connected to the low voltage distributive network. There are a many active solutions at a network level to control harmonics and THD below 10\%. Our proposed method and the simulation analysis shows that harmonics are eliminated at low voltage distribution network due to usage of two pairs of S-T converters. Moreover three phase power converters usage will not make a difference in our low voltage distributive network efficiency.

\section{References}

[1] Du, Mingqiu \& Li, Yan \& Liu, Chunfang \& Liang, Tangjie. (2017). Low-Voltage Analysis of Distribution Network Software Design and Application. Energy and Power Engineering. 09. 183-188.

[2] Watson, Jeremy \& Watson, Neville \& Santos-Martin, David \& Lemon, Scott \& Wood, Alan \& Miller, Allan. (2014). Low Voltage Network Modelling.

[3] Jiang Bo and Wang Jinhui, "Research on harmonic analysis of low voltage distribution networks and its monitoring system," 2016 IEEE Advanced Information Management, Communicates, Electronic and Automation Control Conference (IMCEC), Xi'an, 2016, pp. 1416-1420

[4] Shi Shengyan, Shen Xiaoliu and Gu Yawei, "Research on calculation of low voltage distribution network theoretical line loss based on matpower," 2016 International Conference on Advanced Power System Automation and Protection, Beijing, 2016

[5] Arthur Ekwue ,"Study on low voltage network",International Journal of Renewable Energy Technology, 2014 Vol.5 No.3, pp. $217-228$.

[6] M. Usman, F. Bignucolo, R. Turri and A. Cerretti, "Power losses management in low voltage active distribution networks," 2017 52nd International Universities Power Engineering Conference (UPEC), Heraklion, 2017, pp. 1-6.

[7] J. Dickert, M. Domagk and P. Schegner, "Benchmark low voltage distribution networks based on cluster analysis of actual grid properties," 2013 IEEE Grenoble Conference, Grenoble, 2013, pp. 1-6.

[8] Q. Ke, B. Li, X. Chen and Q. Han, "Research on Energy Efficiency Evaluation of Medium and Low Voltage Distribution Network," 2017 International Conference on Industrial Informatics - Computing Technology, Intelligent Technology, Industrial Information Integration (ICIICII), Wuhan, 2017, pp. 337 341.

[9] Castilla, M., Velasco, M., Miret, J., Martí, P., Momeneh, A.: 'Comparative study of a9ctive power control methods for photovoltaic inverters in low-voltage grids'IET Renew. Power Gener., 2016, 10, (3), pp. 310-318.

[10] Van Roy, J., Leemput, N., Geth, F., Buscher, J., Salenbien, R., Driesen, J.: 'Electric Vehicle Charging in an Office Building Microgrid With Distributed Energy Resources'IEEE Trans. Sustain. Energy, 2014, 5, (4), pp. 1389-1396. 